\title{
O dossiê de registro do Reinado de Nossa Senhora do Rosário em Betim: discursos paralelos ou entrecruzamentos?
}

\author{
The registration dossier from Reinado de Nossa \\ Senhora do Rosário, in Betim: Parallel \\ discourses or crossovers?
}

Aline Pinheiro BRETTAS²

\section{Resumo}

Este artigo objetiva analisar o conteúdo discursivo do Dossiê de Registro do Reinado de Nossa Senhora do Rosário de Betim, produzido pela Fundação Artística Cultural de Betim. A metodologia consiste na adoção de pontos de análise - sujeitos do discurso, hierarquias, pontos de incompatibilidade e de equivalência -, com base na abordagem elaborada por Michael Foucault, no livro "Arqueologia do Saber", publicado em 1972. O dossiê é um documento em constante construção e, neste caso estudado, foi elaborado com a participação da Administração Pública, dos profissionais de mercado e dos próprios congadeiros. Cada um desses atores teve os interesses atendidos, mas nota-se que o primeiro, ainda, desempenha um papel preponderante, por elaborar as leis e os critérios de seleção e de preservação do patrimônio cultural imaterial.

Palavras-chave: Análise de conteúdo. Arquivo. Betim. Patrimônio imaterial. Registro. Reinado de Nossa Senhora do Rosário.

\begin{abstract}
The aim of the article was to analyze the discursive context of the registration dossier from the Reinado de Nossa Senhora do Rosário, in Betim, that was produced by the Artistic-Cultural Foundation of Betim. The methodology consists of the adoption of analysis aspects - subjects of speech, hierarchies, aspects of incompatibility and equivalence - based on the approach developed by Michael Foucalt in his book "Archaeology of Knowledge", published in 1972. The dossier is document under constant development which, in this particular case, includes the participation of the Public Administration, professionals in the market, and the congadeiros; interests of each of these actors were acknowledged, but we noticed that the Public Administration still plays a predominate role as it establishes laws, selects and preserves the criteria for intangible cultural heritage.
\end{abstract}

Keywords: Content analysis. Archive. Betim. Intangible heritage. Records. Reinado de Nossa Senhora do Rosário.

\section{Introdução}

Busca-se, neste artigo, analisar o conteúdo de um dossiê de registro de patrimônio imaterial. Para tanto, precisa-se compreender o que representa este docu- mento, e como se deu sua consolidação no Brasil e em Minas Gerais.

No Brasil, o Decreto $n^{\circ} 3.551$, de 4 de agosto de 2000, criou o Instituto do Registro: um recurso de re-

\footnotetext{
1 Artigo elaborado a partir da tese em andamento de A.P. BRETTAS, intitulada"Os registros dos congados de Belo Horizonte e Betim: novas abordagens em relação à preservação do patrimônio cultural imaterial", Universidade Federal de Minas Gerais, 2013.

2 Universidade Federal de Minas Gerais, Escola de Ciência da Informação, Programa de Pós-Graduação em Ciência da Informação. Av. Antônio Carlos, 6627، Pampulha, 31270-901, Belo Horizonte, MG, Brasil. E-mail: <apb27@hotmail.com>.

Recebido em 11/3/2013, reapresentado em 29/5/2013 e aceito para publicação em 24/7/2013..
} 
conhecimento e valorização do patrimônio imaterial. O registro corresponde à identificação e ao reconhecimento do bem intangível - mediante documentação produzida por meios escritos e audiovisuais -, e da percepção do passado e do presente de tais manifestações, conforme é determinado no Art. 10:

\begin{abstract}
Art. 1 Fica instituído o Registro de Bens Culturais de Natureza Imaterial que constituem patrimônio cultural brasileiro.

$\S 1$ 을 Ese registro se fará em um dos seguintes livros:

I - Livro de Registro dos Saberes, onde serão inscritos conhecimentos e modos de fazer enraizados no cotidiano das comunidades;

II - Livro de Registro das Celebrações, onde serão inscritos rituais e festas que marcam a vivência coletiva do trabalho, da religiosidade, do entretenimento e de outras práticas da vida social;

III - Livro de Registro das Formas de Expressão, onde serão inscritas manifestações literárias, musicais, plásticas, cênicas e lúdicas;

IV - Livro de Registro dos Lugares, onde serão inscritos mercados, feiras, santuários, praças e demais espaços onde se concentram e reproduzem práticas culturais coletivas (Brasil, 2007, online).
\end{abstract}

Os bens selecionados para registro, no Instituto do Patrimônio Histórico e Artístico Nacional (IPHAN), são inscritos em livros assim denominados: a) Saberes (registro de conhecimentos e modos de fazer); b) Celebrações (festas, rituais e folguedos); c) Formas de expressão (manifestações literárias, musicais, plásticas, cênicas e lúdicas); d) Lugares (espaços onde se concentram e reproduzem práticas culturais coletivas).

Em Minas Gerais, os livros de registros dos bens culturais de natureza imaterial apresentam as mesmas categorias dos livros do IPHAN, e foram criados pelo Decreto $n^{\circ}$ 42.505, de 15 de abril de 2002:

Art. $1^{\circ}$ - Ficam instituídas as formas de registro de bens culturais de natureza imaterial que constituem o patrimônio cultural de Minas Gerais.

$\S 1 \circ \mathrm{O}$ registro dos bens culturais de natureza imaterial que constituem patrimônio cultural mineiro será efetuado em quatro livros, a saber:
I - Livro de Registro dos Saberes, onde serão inscritos conhecimentos e modos de fazer enraizados no cotidiano das comunidades;
II - Livro de Registro das Celebrações, onde serão inscritos rituais e festas que marcam a vivência coletiva do trabalho, da religiosidade, do entretenimento e de outras práticas da vida social;

III - Livro de Registro das Formas de Expressão, onde serão inscritas manifestações literárias, musicais, plásticas, cênicas e lúdicas;

IV - Livro de Registro dos Lugares, onde serão inscritos mercados, feiras, santuários, praças e demais espaços onde se concentram e se reproduzem práticas culturais coletivas (Minas Gerais, 2007, online).

Entretanto, o Instituto Estadual de Patrimônio Histórico e Artístico de Minas Gerais (IEPHA/MG) adotou algumas medidas peculiares, por meio do repasse de verbas do Imposto de Circulação sobre Mercadorias e Serviços (ICMS) Cultural: uma modalidade orientada exclusivamente para o financiamento das municipalidades. Os municípios são estimulados a formular e a implementar uma política pública de patrimônio cultural, a partir de critérios estabelecidos por aquele Instituto. A definição da agenda para política pública municipal de patrimônio do IEPHA é evolutiva, e vai respondendo a atualização conceitual no campo do patrimônio e às demandas e especificidades colocadas pelas cidades mineiras no processo de construção de sua política de patrimônio cultural. Para fazerem jus ao recebimento dos recursos do ICMS disponibilizados ao patrimônio cultural, os municípios devem cumprir as metas estabelecidas progressivamente pelo governo estadual. A comprovação de atuação é realizada por meio da apresentação de documentos que devem seguir os modelos divulgados pelo IEPHA. Os trabalhos - dossiês de registro e de tombamento, Inventários do Patrimônio Artístico e Cultural (IPAC), projetos de educação patrimonial e propostas de legislação urbanística, mecanismos urbanísticos e outras legislações complementares -, são assumidos pelos profissionais de mercado, quais sejam: arquitetos e historiadores contratados pelas prefeituras. Em 2009, a Lei Estadual no 18.030, de 12 de janeiro, determinou o encaminhamento de repasse de verbas do ICMS cultural aos bens imateriais registrados, por meio de dossiê de registro (Minas Gerais, 2009).

O dossiê, por sua vez, é um procedimento administrativo pelo qual o Estado reconhece, protege e inscreve, em livro próprio o patrimônio cultural, bens de 
natureza imaterial, com o objetivo de garantir a continuidade de expressões culturais. A proposta geralmente é feita pelos membros dos conselhos do patrimônio cultural, mas também pode ocorrer por parte de órgãos e entidades públicas da área de cultura, educação ou turismo ou por entidade ou associação civil produtora da manifestação cultural sobre a qual se pleiteia o registro.

O dossiê de registro demanda um considerável trabalho de campo e pesquisa, com a atuação de uma equipe composta por arquitetos, historiadores e/ou antropólogos, que devem acompanhar, analisar e documentar as diversas práticas culturais. Existe, também, um modelo a ser seguido, com uma metodologia elaborada para direcionar o trabalho executado. O modelo exige o seguinte conteúdo básico: contextualização (histórica/ antropológica/outras); informações sobre o objeto (histórico, descrição, relação da atividade com o lugar, identificação dos agentes envolvidos, recursos, produtos, público alvo, identificação de atividades correlatas); inventário do bem cultural e dos bens associados; medidas de salvaguarda e valorização; documentação fotográfica; registro audiovisual; pareceres; atas; notificações, comunicações e recibos.

\section{A atuação da Funarbe na produção do dossiê de registro}

Betim iniciou, pioneiramente, uma política municipal para preservação do patrimônio imaterial. Em 2000, o Decreto no 16.389, de 26 de outubro, instituiu o Registro de Bens Culturais, e a criação dos seguintes livros (Betim, 2000):

1) Referências naturais, paisagísticas, urbanísticas, arquitetônicas e da cultura material, para registro das referências naturais e paisagísticas, dos conjuntos urbanos, edificações isoladas ou em conjunto, monumentos e demais objetos;

2) Práticas comunitárias, esportivas e culturais, para registro dos espaços e das práticas comunitárias, esportivas e culturais coletivas que neles se reproduzirem;

3) Saberes, para registro dos saberes e modos de fazer enraizados no cotidiano das comunidades;

4) Festas, para registro das festas, celebrações e folguedos que marcam espiritualmente a vivência do trabalho, da religiosidade, do entretenimento e da vida cotidiana;
5) Linguagens, para registro das linguagens literárias, musicais, iconográficas e cenográficas.

A Fundação Artístico Cultural de Betim (Funarbe) desenvolveu mecanismos para o registro das dimensões intangíveis do patrimônio cultural no ano 2000, além dos propostos pelo IEPHA. Mesmo com a regulamentação do registro pelo Governo Federal, a Funarbe já havia adotado sua legislação sobre patrimônio cultural e iniciado o registro do primeiro bem cultural nessa categoria: o Salão de Encontro. Conforme uma historiadora do órgão (Gomes, 2011), vários elementos eram tangíveis, assim como muitos de seus espaços e objetos de aprendizagem, interação e lazer. A metodologia foi concebida e desenvolvida por uma equipe do Núcleo de Estudos em Antropologia e Desenvolvimento, vinculada à Universidade Federal de Minas Gerais (UFMG), que, nesse período, era conveniada à Funarbe.

O Instituto Estadual de Patrimônio Histórico e Artístico, entretanto, recuperou uma atuação mais preponderante nas políticas de preservação do patrimônio cultural (inclusive o imaterial) na cidade quando, em 2009, o município retomou a experiência de registro da intangibilidade no bem cultural. Aquele instituto, por meio da Deliberação do Conselho Estadual de Patrimônio Cultural (CONEP), no 1/2009, determinou a reversão dos recursos do ICMS Cultural ao município que registrar bens de natureza imaterial:

O Conselho Estadual do Patrimônio Cultural CONEP -, no uso de suas atribuições, notadamente no exercício da competência prevista no inciso I do art. $2^{\circ}$ da Lei Delegada no 170, de 25 de janeiro de 2007, e no Decreto n 44.785, de 17 de abril de 2008, em conformidade com a Lei no 18.030, de 12 de janeiro de 2009, e legislação aplicável, em reunião extraordinária realizada em 30 de junho de 2009, deliberou aprovar as seguintes normas relativas à distribuição do ICMS em Minas Gerais - Critério do Patrimônio Cultural, Processo CONEP 1/2009:

Art. 10 - Fará jus à pontuação prevista no Anexo II da Lei no 18.030/2009 - Atributos: Núcleo Histórico (NH), Conjunto Paisagístico (CP), Bens Imóveis (BI), Bens Móveis (BM), Registro de Bens Culturais Imateriais (RI), Inventário de Proteção ao Acervo Cultural (IN), Educação Patrimonial (EP), Existência de Planejamento e Política Municipal de Proteção do Patrimônio Cultural (PCL), Fundo 
de Preservação do Patrimônio Cultural (FU) e Atuação na Preservação de seus Bens Culturais, o município que atender às exigências de que trata esta Deliberação.

Art. $2^{\circ}$ - A entrega da documentação deverá ser feita via Sedex, com comprovante de postagem e de recebimento, tendo como destino o IEPHA/ MG. Somente será aceita a documentação postada até 15 de Janeiro de cada ano, encaminhada ao IEPHA/MG - ICMS Patrimônio Cultural [...]. Parágrafo Único - As informações de caráter administrativo deverão ser assinadas por autoridade municipal (prefeito municipal ou vice-prefeito) e as de caráter técnico, pelos técnicos responsáveis pelo trabalho. No caso de laudo de estado de conservação de estruturas arquitetônicas, deverá ser indicado o número da habilitação técnica registrada junto ao órgão específico (Instituto Estadual de Patrimônio Histórico de Minas gerais, 2009, online).

Entretanto, a Funarbe optou por princípios próprios, ainda que aderindo à recomendação do IEPHA. De acordo com Gomes (2011), o critério de seleção de bens a serem registrados seria: antiguidade/perenidade dos bens culturais; descentralização dos bens em destaque no acervo de memória da cidade, por meio da escolha de bens identificados no inventário participativo do patrimônio cultural das regionais administrativas de Betim. Pelo primeiro critério, foi escolhido o Reinado de Nossa Senhora do Rosário; pelo segundo, foram selecionados a Folia de Reis de Santo Afonso, Coral Tangarás de Santa Isabel e a Banda Musical Nossa Senhora do Carmo. A metodologia de registro do Reinado de Nossa Senhora do Rosário seguiu as diretrizes do IEPHA, porém, a aplicação foi efetivada pela própria equipe da Funarbe, que acompanhou durante o ano de 2009 o cotidiano da manifestação cultural, além de ter realizado um estudo antropológico e histórico do bem. Durante o trabalho, os registros da literatura memorialística sobre Betim foram cotejados, além de uma pesquisa sobre as histórias afrodescendentes, com alusões ao conhecido patriarca do congado, Joaquim Nicolau. Entrevistas com protagonistas locais do Reinado foram gravadas e transcritas. Além disso, como parte da exigência do IEPHA, estudos sobre a manifestação em Minas Gerais e suas correlatas em outros estados brasileiros foram consultados.

O primeiro registro realizado pela equipe, do Reinado de Nossa Senhora do Rosário, promoveu um movimento inédito na Fundação, de siste- matização de dados e documentos sobre a manifestação cultural conhecida como congado. Milhares de fotografias, que registram o bem desde os anos 50, foram organizadas cronologicamente e em ordem temática. Essas temáticas não raro caracterizaram categorias de análise do bem durante o processo de registro. Apenas através das fotos pudemos observar elementos da celebração, como o ritual de coroação de reis e rainhas, ausente das atividades nos anos de registro. Foi também através do registro fotográfico que pudemos ver as mudanças de percurso do Reinado no centro de Betim, nas últimas décadas, e inovações introduzidas na celebração (Gomes, 2011, p.116).

O dossiê de registro foi um instrumento que aprofundou as relações entre a Funarbe e a Irmandade do Rosário. As reivindicações desta última entidade começaram a ser compreendidas, o que possibilitou a elaboração de medidas de salvaguarda e planos de educação patrimonial, para se valorizar o bem cultural que, conforme Gomes (2011, p.117), apresenta uma singularidade:

[...] o fato de que as celebrações anuais são protagonizadas por diversos grupos, guardas de congo, Moçambique, marujos e catopés não necessariamente oriundas da mesma tradição religiosa ou do mesmo clã. Essa característica torna necessária a mediação dos conflitos entre os grupos e desafia a gestão do apoio institucional oferecido pela Funarbe e outros setores da Prefeitura de Betim ao Reinado do Rosário [...]. Em Betim, várias são as anfitriãs e várias são as convidadas. Resulta em um belíssimo espetáculo de cor e som, com um número elevado de grupos, vinte em média nos últimos anos, cujo interior está eivado por fissuras as quais é necessário mediar.

Interessante observar que Gomes (2011, p.119) faz uma crítica à metodologia de registro, ao afirmar que não é razoável cindir os bens patrimoniais em suas dimensões tangíveis e intangíveis. Enfatiza, também, os debates sobre os riscos de se patrimonializar tudo, ou a tudo fossilizar, "[...] mas, especialmente para municípios como Betim, onde cada nova escolha regional sobre desenvolvimento econômico e social avassala praticamente todo o acervo da formação anterior, aquilo que segue nos corações e mentes constitui o maior acervo patrimonial local". Percebe-se, por esse comentário, que a tradição pode ser perdida, à medida que a urbanização 
acrescenta novos valores sociais, em detrimento dos antigos, relacionados à devoção religiosa ou a qualquer outra manifestação de cunho popular, que se perpetua pela oralidade.

Deve ser salientado que o contato da Funarbe com o Núcleo de Estudos de Antropologia e Desenvolvimento (NEAD), além da própria formação da equipe técnica da Fundação, possibilitou que esta produzisse um dossiê de conteúdo mais aprofundado, baseado em produções acadêmicas e metodologias não somente historicistas, mas também antropológicas. Informações importantes, relativas aos elementos simbólicos da celebração, foram abordadas de modo cuidadoso, com argumentações teóricas percebidas em uma relação de convivência entre a Funarbe e os congadeiros. O dossiê apresentou o seguinte direcionamento: história dos congados e reinados; histórico de Betim; o epicentro do Reinado; história do Reinado; a relação do Reinado com Betim; descrição dos lugares e suportes físicos; agenciamento do espaço para a atividade; a ocupação espacial; formato, conteúdos, narrativas, significados; os protagonistas: trajetórias, papéis, funções, organização; os recursos para a realização da celebração; os produtos do Reinado; relações com o público; inventário; identificação de atividades correlatas; delimitação e descrição da área de ocorrência; salvaguarda e valorização; documentação fotográfica; registro audiovisual; referências.

Quanto ao interesse na preservação e continuidade do Reinado de Nossa Senhora do Rosário, isso se deve ao fato de esta manifestação, segundo a equipe da Funarbe, ser uma das mais importantes festas populares no calendário de eventos de Betim. Entretanto, devido à necessidade de iniciação ritual para compreender o evento, a festa tem atraído pouquíssimo público nos últimos anos, exceto os diretamente envolvidos - os próprios congadeiros. Para modificar essa situação, uma hipótese da equipe do órgão é a existência de um público remanescente para a festa em diversas regiões da cidade, e também nos municípios vizinhos, apesar de ser um público residual; esse público poderia participar do evento desde que conhecesse sua programação com antecedência e pudesse contar com apoios diversos para se deslocar das várias regiões da cidade até o cenário da festa. A Funarbe e a Prefeitura de Betim apresentam a sua própria justificativa, no que tange à realização de ações para continuidade da celebração, considerando as questões históricas e econômicas dos envolvidos:

O Brasil tem buscado maneiras de acessar suas comunidades afrodescendentes, no sentido de a elas orientar políticas sociais que corrijam as distorções extensas e profundas causadas à sociedade brasileira pelo legado da escravidão. As manifestações da cultura religiosa dessas comunidades, dentre elas o chamado congado, estão entre as principais vias de acesso a essas comunidades.

Na Irmandade de Nossa Senhora do Rosário de Betim, são notórios os casos de limitada inserção social de seus protagonistas, que, por isso, ficam bastante vulneráveis a manipulações de grupos empoderados na cidade. Há extensos problemas quanto à alimentação, habitação, saúde, especialmente saúde bucal, alfabetização e letramento, participação no mercado de trabalho, etc.

A proposta da Equipe Referência em Memória e Patrimônio Cultural é uma parceria inicial com a SEMAS [Secretaria Municipal de Assistência Social de Betim] para identificar as necessidades de desenvolvimento social no interior das diversas Guardas do congado betinense. Isso deverá ser feito não apenas em relação às lideranças, mas também em relação a todos os integrantes das Guardas, com imediato encaminhamento às demais Secretarias parceiras desta ação. A alfabetização e letramento dos protagonistas desta manifestação é fundamental para o projeto de construção da autonomia defendido pela Equipe Referência em Memória e Patrimônio Cultural.

Deve ser registrado que, nesse sentido, o Ministério do Desenvolvimento Social, em parceria com a Unesco33, está inventariando as comunidades tradicionais de terreiros, do ponto de vista

\footnotetext{
3 O Ministério do Desenvolvimento Social e Combate à Fome (MDS) e a Organização das Nações Unidas para a Educação, Ciência e Cultura (UNESCO), em parceria com a Secretaria de Políticas de Promoção da Igualdade Racial (SEPPIR) e a Fundação Cultural Palmares (FCP), realizaram o projeto "Mapeando o Axé: pesquisa socioeconômica e cultural das comunidades tradicionais de terreiro". Trata-se do mapeamento das comunidades tradicionais de terreiro nas capitais e regiões metropolitanas dos estados de Minas Gerais, Pará, Pernambuco, e Rio Grande do Sul. O objetivo do mapeamento é conhecer a realidade dos terreiros dos locais pesquisados. Buscou-se construir um banco de dados que norteará as políticas públicas junto às comunidades de terreiro, com ênfase na promoção da segurança alimentar e nutricional. A pesquisa enfatizou a dimensão comunitária e o caráter étnico, considerando a organização social e o trabalho tradicionalmente desenvolvido pelos povos de terreiro. Os terreiros desempenham um papel extremamente importante na promoção da segurança alimentar e nutricional das comunidades em que vivem e atuam (Brasil, 2011).
} 
da segurança alimentar, o que, em médio prazo, beneficiará alguns dos grupos ligados ao Reinado de Nossa Senhora do Rosário de Betim. A Funarbe e a Pró-coordenadoria de Igualdade Racial são parceiras neste projeto (Prefeitura Municipal de Betim, 2010, p.7).

O dossiê de registro do Reinado foi encaminhado em 2009 ao IEPHA/MG, para aprovação e nomeação do bem como "Patrimônio Imaterial do Município de Betim", em 2010. É sobre este documento que se elabora um levantamento de informações, tomando por método norteador alguns elementos trazidos por Foucault (1972), em sua obra "A arqueologia do saber" para formulação de algumas categorias que nortearão esta análise.

Os congadeiros se expressaram no dossiê por meio de depoimentos orais. Mas nota-se que a interpretação de suas falas, bem como de seus rituais e práticas que também aparecem em registros fotográficos e audiovisuais, não é feita pelos próprios, mas principalmente pela Funarbe.

\section{Os discursos registrados}

O dossiê de registro pode ser considerado uma construção discursiva, onde coexistem os discursos emitidos por vários sujeitos envolvidos na sua elaboração. Foucault (1972) elaborou algumas observações para a sua abordagem de análise de discurso. Não se utilizou uma metodologia nos moldes do autor, mas suas reflexões possibilitaram a elaboração de alguns pontos de apreciação, para compreender melhor os discursos dos agentes que participaram direta e indiretamente da elaboração dos registros, e as relações entre eles:

A análise do campo discursivo [...] trata-se de compreender o enunciado na estreiteza e singularidade de seu acontecimento; de determinar as condições de sua existência, de fixar seus limites da forma mais justa, de estabelecer suas correlações com os outros enunciados a que pode estar ligado, de mostrar que outras formas de enunciação exclui [...] deve-se mostrar porque não poderia ser outro, em que exclui qualquer outro, como ocupa, no meio dos outros e relacionado a eles, um lugar que nenhum outro poderia ocupar [...] qual é essa singular existência, que vem à tona no que se diz e em nenhuma outra parte? (Foucault, 1972, p.39).
Mediante tais considerações, procura-se identificar os discursos - emitidos pela escrita, pela fotografia, pela filmagem e por depoimentos orais (gravados e transcritos) -, que influenciaram a estruturação formal e conteudista do Dossiê de Registro do Reinado de Nossa Senhora do Rosário de Betim.

\section{Quem fala?}

Essa é uma pergunta formulada por Foucault (1972), que caracteriza a formação de uma modalidade enunciativa, a primeira que revela os sujeitos que discursam e que delineiam o encadeamento dos enunciados emitidos:

Quem, no conjunto de todos os indivíduos-que-falam, está autorizado a ter esta espécie de linguagem? Quem é seu titular? Quem recebe dela sua singularidade, seus encantos e de quem, em troca, recebe, senão sua garantia, pelo menos a presunção de que é verdadeira? Qual é o estatuto dos indivíduos que têm - e apenas eles - o direito de regulamentar ou tradicional, juridicamente definido ou espontaneamente aceito, de proferir semelhante discurso? (Foucault, 1972, p.65).

Ao consultar o referido dossiê, depara-se com discursos de proveniência, apontada como direta ou indireta. Considera-se o discurso direto, quando são expressos no documento, verbalmente ou por imagens, as falas de determinados atores. O indireto, por seu lado, é quando nota-se o discurso por parte de instituições que determinaram as condições para a construção do documento.

No primeiro caso, encontra-se os produtores que participaram diretamente na elaboração do documento. Compõem-se, assim, a citada "ficha técnica" da montagem do dossiê: a participação de historiadores do Departamento de Planejamento e Pesquisa da Funarbe e de geógrafos, para o levantamento e sistematização de dados de aspectos geográficos e históricos do município e dados de aspectos históricos e antropológicos do Reinado; formatação do documento; revisão técnica (um cientista social) e linguística (historiadora da Funarbe); transcrição das entrevistas (historiadores e estagiários da Funarbe); consultoria da Miguilim Assessoria Cultural Ltda. (profissionais arquitetos para a descrição dos espa- 
ços ocupados pelo Reinado); profissionais para a edição da documentação audiovisual.

Houve também a equipe técnica que montou o inventário dos bens culturais (imóveis, móveis e intangíveis), que compõem o Reinado: os elaboradores também foram os funcionários daquela fundação, com a participação de dois fotógrafos e a consultoria de um cientista social.

O dossiê, na íntegra, também contou com uma consultoria técnica, representada por um cientista social formado pela UFMG. Tanto a equipe da Funarbe quanto o cientista também emitiram um parecer técnico, para justificar o registro da celebração. Encontram-se, também, os pareceres dos componentes do Conselho Deliberativo do Patrimônio Cultural de Betim, também favoráveis.

No que tange ao aspecto burocrático exigido pelo IEPHA, o presidente da Irmandade de Nossa Senhora do Rosário também assinou uma notificação, de concordância com o registro. O Presidente do Conselho Deliberativo do Patrimônio Cultural de Betim, o Vice-Prefeito e a Prefeita de Betim fizeram o mesmo; sendo que o primeiro também precisou fazer um pronunciamento sobre o documento, e foi responsável também em assinar a homologação. Para oficialização, o registro foi inscrito no Livro de Festas do Município, e publicado no órgão oficial de Betim, em 22 de dezembro de 2009.

Porém, a aprovação por parte do IEPHA foi fundamental. O então gerente de Cooperação Municipal daquele órgão precisou também avaliar o conjunto de peças legais, e o reconheceu como válido.

Sobre os chamados "protagonistas" do Reinado - termo este utilizado pelos autores do dossiê -, localiza-se os depoimentos de algumas lideranças: capitães dos ternos que compõem a manifestação, o rei e a rainha conga, o presidente da Irmandade. Os depoimentos foram gravados e transcritos, dispostos em anexo ao dossiê. Entretanto, encontram-se alguns trechos dos mesmos no corpo do registro, principalmente nos campos que tratam do histórico e da descrição da manifestação. Foram respondidas questões sobre os elementos materiais e simbólicos que compõem os rituais, sobre a transmissão dos saberes da manifestação, e sobre a relação dos congadeiros com a Funarbe e a Prefeitura de Betim.
Os congadeiros e a equipe da Funarbe também discursaram por ocasião da filmagem da reunião feita com os congadeiros, realizada no dia 24 de novembro de 2009. As lideranças dos ternos, em um mesmo espaço, falaram da formação dos respectivos grupos, entoaram cânticos em homenagens à Virgem Maria, narraram e desempenharam performances relativas aos elementos simbólicos do Reinado. No vídeo, também foram apresentados depoimentos das funcionárias da Funarbe, explicando a respeito da construção da Capela de Nossa Senhora do Rosário, templo onde são celebrados ritos importantes da manifestação, como a missa conga.

Indiretamente, percebe-se a participação crucial do IEPHA, visto que ele elaborou o modelo do dossiê de registro, e determinou os parâmetros para a preservação do bem, para torná-lo patrimônio imaterial do município, e para que este bem recebesse, em decorrência do registro, os recursos do ICMS.

Entretanto, para o IEPHA e a Funarbe atuarem, precisaram de um respaldo jurídico, por meio de leis que regulamentaram a preservação do patrimônio. No dossiê, foram citados: a lei que institui a proteção do patrimônio cultural de Betim - a Lei Municipal no 2.944, de 24 de setembro de 1996; e o Decreto Municipal no 16.389, de 26 de outubro de 2000, que regulamentou aquela lei, ambos determinados pela Prefeitura de Betim (Betim, 1996, 2000). A ação do IEPHA, por sua vez, já foi regulamentada por leis e normas mineiras que não foram citadas no documento, mas apontaram o direcionamento que a Funarbe deveria adotar, no que tange não só à elaboração do dossiê de registro do Reinado, mas também à preservação dos bens culturais do município e projetos de educação patrimonial: uma delas se trata da Lei Estadual no 18.030, de 12 de janeiro de 2009, que dispõe sobre a distribuição da parcela da receita do produto da arrecadação do ICMS pertencente aos municípios, assinada pelo Governador do Estado de Minas Gerais; a outra trata da Deliberação normativa no 1, de 30 de junho de 2009, que atua em conformidade com a Lei 18.030/ 2009, e com base nesta determina o planejamento de política municipal de proteção do patrimônio cultural e estabelece os modelos de todos os trabalhos realizados para tal fim, inclusive a estrutura do dossiê de registro de patrimônio imaterial (Minas Gerais, 2009). Esta deliberação foi elaborada pelo CONEP, um órgão colegiado, 
deliberativo, subordinado à Secretaria de Estado de Cultura, ao qual compete deliberar sobre diretrizes, políticas e outras medidas correlatas à defesa e preservação do patrimônio cultural do Estado de Minas Gerais (Conselho Estadual do Patrimônio Cultural, [200-?]).

Assim, considerando essas informações para responder a pergunta inicial: quem fala, o titular, o que detém o estatuto jurídico é a Administração Pública de Minas Gerais, representada pelo IEPHA, com a intermediação do CONEP e da Funarbe. O registro dos depoimentos dos "protagonistas" do Reinado, a princípio, foi feito para historicizar e descrever o bem cultural, mas a participação das lideranças do congado, apesar de fundamental, posicionou-se de forma secundária, na construção do registro, para responder uma demanda dos produtores do dossiê.

\section{A tessitura das relações entre os sujeitos}

A formação conceitual de um discurso, conforme Foucault (1972) é constituído por um feixe de relações. O que pertence a uma formação discursiva e o que permite delimitar o grupo de conceitos é a maneira pela qual eles são relacionados uns aos outros. Uma análise do conteúdo do discurso envolve outros elementos que identifiquem a posição dos sujeitos na sua construção:

[...] tentamos determinar segundo que esquemas (de seriação, de grupamentos simultâneos, de modificação linear ou recíproca) os enunciados podem estar ligados uns aos outros em um tipo de discurso [...]. Esses esquemas permitem descrever [...]. sua dispersão anônima através de textos, livros e obras [...] (Foucault, 1972, p.75).

Como se percebe, há uma variedade de sujeitos que participaram da produção do dossiê, com respectivos discursos. Pretende-se discorrer a respeito da posição que esses discursos ocupam, no feixe das relações inseridas nas políticas de proteção ao patrimônio em Minas Gerais; e para tanto se trabalhou com um direcionamento também sugerido por Foucault (1972).

\section{Hierarquias, pontos de incompatibilidade e pontos de equivalência}

Foucault (1972) propõe-se a analisar o discurso minuciosamente, e adota como objetos de pesquisa fontes diversas e oriundas de instituições, grupos sociais, organizações separadas, para se compreender as relações discursivas entre elas.

Verifica-se no dossiê a existência de grupos distintos, cujos discursos registrados corroboraram para a consecução final do material analisado. Intenciona-se mostrar os pontos de incompatibilidade e de equivalência entre tais discursos, e se há uma hierarquia entre eles - para conseguir detectar se os protagonistas do Reinado são ouvidos, para efetivar a preservação da celebração. Algumas situações apresentadas podem comportar essas duas posições (incompatibilidade e equivalência), por isso, não serão apresentados em termos separados.

[...] os diferentes níveis assim definidos não são independentes uns dos outros [...] as escolhas estratégicas não surgem diretamente de uma visão de mundo ou de uma predominância de interesses que pertenceriam mais propriamente, a este ou aquele sujeito-que-fala; mas que sua possibilidade mesma é determinada por pontos de divergência no jogo dos conceitos; [...] os conceitos não eram formados diretamente no fundo aproximativo, confuso e vivo das ideias, mas a partir das formas de coexistência entre os enunciados; quanto às modalidades de enunciação, vimos que eram descritas a partir da posição que ocupa o sujeito em relação ao domínio de objetos de dependências: todas as posições do sujeito, todos os tipos de coexistência entre enunciados, todas as estratégias discursivas não são igualmente possíveis, mas somente as que são autorizadas pelos níveis anteriores [...]. Os níveis não são, pois, livres, uns em relação aos outros e não se desenvolvem segundo uma autonomia sem limite: da diferenciação primária dos objetos à formação das estratégias discursivas existe toda uma hierarquia de relações (Foucault, 1972, p.90).

Entre os congadeiros e o Poder Público (especialmente representado pelo IEPHA e pela Funarbe), primeiramente, observa-se a relação que ambos têm com a manifestação. Para os primeiros é um ato de devoção, de fé. Eles não enxergam a manifestação como uma prática cultural, muito menos como bem patrimonial; ao contrário do Poder Público, que selecionou o Reinado, por meio de critérios jurídicos, técnicos e políticos, para torná-lo patrimônio imaterial do município de Betim. 
No dossiê, hierarquicamente, considerando-se o contexto que propiciou a sua elaboração, prevalece a concepção de bem patrimonial, adotado pela política de preservação do patrimônio em Minas Gerais. Essa distinção comprova a afirmação de Fonseca (1997) sobre a diferença entre bem cultural e bem patrimonial: a intermediação do Estado, por meio da atuação de agentes autorizados e de práticas socialmente definidas e juridicamente regulamentadas, contribui para fixar sentidos e valores. Este, para ser considerado cultural, deve ter enfatizado o seu valor simbólico, enquanto referência a significações por ordem da cultura.

Outro elemento incompatível é a mencionada dependência da Irmandade em relação à Funarbe, para obter recursos, em detrimento de ações tradicionais existentes no congado e que colaboravam para o desenvolvimento da sociabilidade entre os praticantes da manifestação. Sob o ponto de vista da Funarbe, é um fator que precisa ser trabalhado, aos poucos, com os próprios congadeiros, por meio de estímulos sutis e projetos de educação patrimonial, além de tentar regularizar o Cadastro Nacional de Pessoa Jurídica (CNPJ) da Irmandade, para que eles tenham autonomia jurídica para capitação de recursos. Pelos congadeiros, com exceções, parece que esse auxílio prestado foi incorporado e aceito como legítimo, visto que torna alguns momentos da celebração mais confortáveis. Em alguns depoimentos, percebe-se que esse subsídio é visto como uma necessidade para obtenção de recursos básicos, como transporte para outras cidades e alimentação. Em outros momentos, porém, tal interferência externa, no passado, apresentou problemas para os congadeiros, no que diz respeito ao encaminhamento dos recursos; houve também uma alusão a certo autoritarismo da Funarbe, quando esta começou a promover e trabalhar na organização do evento (no início da década de 1990) e chegou a proibir uma tradição (pedir esmolas e doações para a festa).

Cabe ressaltar que está se deparando com gestões diferentes, no mesmo órgão. A equipe que começou a trabalhar com o Reinado, no momento em que a Funarbe foi fundada, em 1987, parecia ter uma postura diferente da equipe atual, que assumiu em 2009. A primeira parece, pelos depoimentos dos congadeiros, ser mais intervencionista e austera; a atual, por outro lado, mostra-se mais maleável e aberta ao debate com os congadeiros e, conforme citou-se anteriormente, propõe-se, por meio do diálogo, estímulo indireto e ações de educação patrimonial, tornar a posição da Irmandade e dos congadeiros mais pró-ativa, na elaboração do registro e em outras ações de fomento à celebração.

Essa posição de dependência foi ressaltada pelo próprio Presidente da Irmandade, por acreditar que, em alguns momentos, os congadeiros se excediam nos pedidos. Essa dependência, entretanto, não parece ser consenso entre todos os congadeiros. Uma das lideranças afirmou não estar empenhada em fazer a festa por obrigação em relação à Funarbe (por este ser um evento que consta no calendário da cidade), mas, sim, quando tiver todos os preparos necessários, inclusive os espirituais. Uma das capitãs já ressalta que sua guarda procura realizar outras atividades para obtenção de recursos, para não depender exclusivamente da Fundação.

A equipe técnica da Funarbe, mesmo reconhecendo essa dependência, percebe que um auxílio ainda é necessário, e que alguns recursos fornecidos - como o transporte -, facilitam a realidade vivida pelos congadeiros, que sempre passam por muitas dificuldades financeiras, e concordam com eles que, um conforto trazido pela contemporaneidade, também não é prejudicial.

A posição do IEPHA, nesse assunto, não é compreendida diretamente no documento. De qualquer modo, pelo fato do Instituto ser necessário para aprovar o registro e destinar os recursos do ICMS, inclusive exigindo um relatório anual de prestação de contas, percebe-se que há no órgão uma postura mais presente e incisiva, pois esse acompanhamento constante é essencial para aprovar os métodos de salvaguarda, propostos neste caso pela Funarbe. Deve-se reconhecer que esta atitude pode ser interessante para valorizar a manifestação e promover sua continuidade; mas por outro lado, mostra-se muito empresarial, com foco em resultados. Uma manifestação cultural e religiosa, por sua imaterialidade característica, é fluida e pode se modificar por si só, não deve prestar contas como um filho faz a um pai, ou como um subordinado faz ao seu gerente.

Nota-se, porém, que os congadeiros em seus depoimentos não mencionam o IEPHA; eles enxergam a Funarbe como o órgão público que, além de trabalhar na organização e promoção do evento (fato este que se 
iniciou antes mesmo da política de ICMS cultural), destina os recursos solicitados.

Assim, parece menos perceptível a ocorrência de uma relação de hierarquia, mas parece haver, nesse caso, uma supervalorização das vontades dos congadeiros, no sentido de atender seus desejos; ainda que haja a tentativa da Funarbe em estimular uma ação mais incisiva por parte dos protagonistas do Reinado, em prol da manifestação em que eles são os maiores interessados. A Funarbe, neste sentido, mostra-se como um agente de intermediação para essa mudança; o IEPHA, por sua vez, por meio da política de repasse de verbas do ICMS, pode ter provocado a dependência econômica e estrutural da manifestação, ainda que indiretamente.

Outro ponto divergente é a diferença entre as estruturas de registro, a deliberada pelo CONEP/IEPHA e a adotada pela Funarbe. A primeira foi uma diretriz que fundamentou todo o trabalho, cujos campos deveriam ser preenchidos, sujeitos à aprovação, para patrimonialização do Reinado e repasse de verbas. Para conquista desses benefícios possibilitados pelo IEPHA, a Funarbe precisou seguir esse modelo; entretanto, pela experiência que a fundação teve com a NEAD/UFMG - que, durante a década de 1990, realizou um levantamento cultural de Betim e do Inventário do Patrimônio Urbano e Cultural do Centro Histórico de Betim (IPUC-Betim), para identificação e caracterização dos elementos do patrimônio urbano e cultural -, a Fundação de Betim procurou seguir uma metodologia de acompanhamento da manifestação durante todo o ano de 2009, buscando um estudo histórico e metodológico da celebração. Ela buscou avançar, além do preenchimento de um dossiê de registro, pois estabeleceu uma relação de convivência com os congadeiros e aprimorou os métodos de pesquisa.

Porém, a base determinante do registro foi estabelecida pelo IEPHA, incluindo também cronogramas de salvaguarda e relatórios anuais; portanto, foi a que se sobrepôs e determinou o encaminhamento de todo o trabalho feito pela Funarbe. Fato este considerado positivo pela sua equipe técnica, mesmo que existam divergências metodológicas e ideológicas, pelo fato de direcionar e estabelecer um cronograma que deve ser cumprido por qualquer gestão que assuma o Poder Público Municipal.
Convém reforçar que o registro precisou de todo um trâmite legal, desde a aprovação no Conselho Deliberativo até a autorização pelo Presidente da Irmandade e publicação no órgão oficial para ser efetivado. Mas as posições, tanto do Conselho quanto da Irmandade, no que diz respeito à estruturação do dossiê mostraram-se inócuas, cujas assinaturas cumpriram apenas uma exigência burocrática.

Outra divergência encontrada, não exatamente no dossiê, mas no contexto de sua produção, são os livros de registro. Conforme apresentado anteriormente, os que foram criados em Betim apresentam uma nomenclatura diferente em relação aos do IEPHA. Para lembrar, os livros de registro do patrimônio imaterial betinense são assim denominados.

1) Referências naturais, paisagísticas, urbanísticas, arquitetônicas e da cultura material;

2) Práticas comunitárias, esportivas e culturais;

3) Saberes;

4) Festas;

5) Linguagens.

Os livros do IEPHA, por sua vez, possuem a mesma denominação que o do IPHAN:
a) Saberes;
b) Celebrações;
c) Formas de expressão;
d) Lugares.

Os livros de Betim foram elaborados antes que os do IEPHA: o primeiro em 2000, e o segundo em 2002. Pela titulação e pelas práticas culturais inseridas nos livros, observa-se muitas semelhanças entre eles (1 e d; 3 e a; 4 e b; 5 e c). Assim, o diferencial dos livros de Betim se encontra no livro sobre práticas comunitárias, esportivas e culturais (item 2); nos outros livros, observa-se uma diferença relativa à terminologia dos títulos.

Neste caso, Betim se diverge também pelo mesmo fator mencionado na estruturação do dossiê: a consultoria do NEAD/UFMG à elaboração dos livros de registro. Os estudos daquele núcleo, sobre patrimônio imaterial, já se mostravam avançados em relação à política de preservação adotada, tanto no Brasil quanto em Minas Gerais. 
Para a elaboração do dossiê, inferiu-se que este fator não exerce uma considerável relevância, visto que a inserção do Reinado em um livro de registro sobre festas ou sobre celebrações não alteraria a produção do material. Mas é interessante frisar o fato de Betim, por meio da Funarbe, ter buscado orientações sobre a política de preservação de patrimônio cultural por meio de parcerias com núcleos acadêmicos, e não terem esperado uma determinação jurídica (estadual ou federal) para ter tido essa preocupação com a área, e buscar desenvolver ações condizentes com teorias elaboradas, por meio de estudos e pesquisas, por profissionais acadêmicos e especializados no assunto. É uma situação peculiar da cidade, cuja iniciativa não é percebida em vários municípios mineiros, que precisaram de uma política de ICMS apresentada pelo Estado para montar um conselho de patrimônio e estruturar suas ações de proteção ao patrimônio. Acentua-se, aqui, a metodologia adotada para a elaboração do Inventário do Patrimônio Urbano e Cultural do Centro Histórico de Belo Horizonte (IPUC-BH), que inspirou o mesmo trabalho feito em Betim e subsidiou a criação dos livros do registro na cidade:

A metodologia do IPUC-BH parte do contexto mais geral - o urbano, com seus múltiplos cruzamentos espaciais, funcionais e simbólicos -, para, num movimento de aproximação, chegar à identificação das referências culturais. Avançando em relação aos inventários estudados, trata a questão da cultura em toda sua abrangência, buscando identificar o processo de formação das identidades sócio-espaciais. Para isso, combinaram-se perspectivas de três áreas disciplinares distintas: a história, a arquitetura e o urbanismo e as ciências sociais.

A pesquisa histórica tem como base dois eixos principais: a história urbana e a história vivida. Os aspectos da ocupação urbana e da dimensão sócio-cultural são abordados através de levantamentos bibliográficos, de fontes escritas e iconográficas, e da realização de entrevistas com moradores, comerciantes e usuários das áreas estudadas.

A pesquisa de arquitetura e urbanismo propõe-se estudar os espaços e edificações significativos, além de analisar as formas representativas de organização e estruturação das regiões, dos processos de apropriação dos espaços e do conjunto das relações e práticas cotidianas. O entendimento da evolução urbana da região e sua relação com o processo de desenvolvimento da cidade constituem ponto-chave dessa análise, permitindo-nos a identificação de áreas e vetores de consolidação e renovação. Com relação ao patrimônio edificado, o enfoque adotado considera as edificações tanto como unidades isoladas como em sua relação com o conjunto urbano, e sua capacidade de gerar ambiências e pontuações no bairro.

A pesquisa sociológica trabalha ao mesmo tempo as micro e macro instâncias, combinando métodos quantitativos e qualitativos, visando apreender as condições diferenciais da relação comportamento / espaço e os processos sociais que derivam de formas distintas de organização e apropriação do espaço do bairro e da cidade (Castriota \& Rugani, 1999, p.3).

Nota-se uma abordagem interdisciplinar que contempla vários aspectos relacionados à formação urbana de Betim, tais como a construção das edificações, a ocupação territorial, a mobilidade dos habitantes e as suas histórias de vida, em decorrência das transformações estruturais pelas quais a cidade passou. Entretanto, apesar dos autores supracitados terem apontado também a necessidade de valorização das formas culturais locais e das manifestações sociais da cultura periférica urbana, houve uma priorização do patrimônio edificado, ainda que considerada a existência de elementos simbólicos na constituição desses bens e as atividades realizadas nos locais inventariados. É mencionada a Capela de Nossa Senhora do Rosário, como principal referencial arquitetônico e histórico de uma das áreas delimitadas:

Na sub-área III, o principal referencial arquitetônico e histórico é a Igreja de Nossa Senhora do Rosário, construída no final do século XIX. Implantada em plano elevado, o adro de dimensões generosas permite a visualização do centro da cidade. É bastante significativo que 19\% das edificações da rua do Rosário sejam datadas dos anos 40 (faces de quadras III-D e III-I), comparado com a taxa de edificações remanescentes desse período nas outras sub-áreas (em torno de 4\%). A permanência das edificações mais antigas aponta para um processo de adensamento mais lento na sub-área III, que só da década de 70 em diante vem apresentando taxas maiores de construção (Castriota \& Rugani, 1999, p.12).

Não se detecta, nesse documento, uma tentativa de trabalhar diretamente com o patrimônio imaterial da 
cidade, muito menos a abertura para o debate com os agentes das manifestações culturais e simbólicas. Nesse sentido, inferi-se que, quando os livros de registro foram criados e as ações de preservação ao patrimônio cultural começaram a ser implantadas em Betim, a participação dos congadeiros pode ter sido limitada, ou até mesmo, inexistente.

Os conflitos internos entre as lideranças e as guardas, por sua vez, foram citadas no dossiê como um elemento que compromete a coesão do grupo e, por consequência, a vitalidade da festa, em rituais específicos, como a Missa Conga; ou até mesmo para a escolha do Presidente da Irmandade, sendo que o atual não é considerado um representante legítimo dos protagonistas do Reinado. Em relação a esse caso, são realizadas ações de educação patrimonial e conscientização pública, para tentar minimizar alguns preconceitos de cunho religioso e discriminatório. Por outro lado, tais conflitos foram mesmo detectados nos depoimentos dos entrevistados (Prefeitura Municipal de Betim et al., 2009), mas não se percebe que este fato é, para eles, um problema que compromete a manutenção da festa; trata-se, de uma divergência, legitimada no inconsciente coletivo do grupo. Em alguns depoimentos, percebe-se a necessidade de se diferenciar o congado das outras tradições de origem afro-brasileira:

Olha eu pelo menos fui criado na católica pra mim não tem religião acima dela par mim não! Entendeu? É uma coisa é uma religião também que essa dança de congado pra mim eu pelo menos não to ali com mal intenção. Durante o tempo que eu to ali, eu to feliz e louvando a deus e nossa Sra., não to pensando nada ruim [...], mas todo mundo é nego que já mexeu, mexe no terreiro, tem gente espiritual, só não entra naquele momento de festa, mas quase a maior parte desse pessoal que dança reinado é espiritismo! Né! quase eles todo, mas falar que tá ali por causa do ramo (Terreiro???) não! [...]. Terreiro é terreiro, festa de congado é festa de congado [...] (Prefeitura Municipal de Betim et al., 2009, p.235).

Em outro depoimento, por outro lado, percebese conflitos familiares em torno de questões espirituais:
Eu começei de velha, eu já tinha aquela mania de ver as coisas, teve uma vez que a gente tava brincando na mangueira, ai veio um calango verde, ele passou na minha mão, ai eu falei com meus irmãos que ia acontecer alguma coisa com mamãe ou com o papai. Ai por falta de sorte minha, mamãe queima com uma taturana no cafezal, ai quando ela veio os meninos pegaram e falaram:"a Efigenia [...] a senhora, é por isso que a lagarta queimou a senhora". Eu nem pensava em nada, é aquelas coisas que a gente tinha, sei lá. Ai depois tudo que acontecia na família, a família acusava que era eu e nisso eu acho que a gente vai pondo uma coisa na cabeça, eu não fiz, mas deus fez [...] (Prefeitura Municipal de Betim et al., 2009, p.238).

Há outros trechos que mencionam uma reserva em relação ao espiritismo e às manifestações de origem mais voltadas para a cosmovisão africana, por parte dos congadeiros próximos ao catolicismo, o que gerou também conflitos familiares. Outros participantes, por outro lado, já vêem com mais naturalidade a relação com a umbanda e o candomblé, e percebem o sincretismo destas expressões religiosas com a devoção santeira:

É porque no candomblé trabalha com os santos, todos os orixás de luzes, que eles trocam de roupa, usam aquelas roupas bonitas e vão dançar, só tem dança no Candomblé e as comidas, as oferendas, mata bichos e tudo. Ea Umbanda não tem as roupas legalmente, trabalha com qualquer linha, a Umbanda trabalha mistura de linhas e o Candomblé é purificado, tem que raspar a cabeça, aquela coisa tudo (Prefeitura Municipal de Betim et al., 2009, p.242).

Existem, também, algumas disputas no momento da procissão, que compõem um rito internalizado pelos congadeiros. Por isso, nesse caso, a Funarbe evita interferir nesses conflitos pontuais, agindo em conformidade com a postura dos manifestantes. Segue um trecho da entrevista, incluindo as questões. Para facilitar a compreensão, denomina-se o Entrevistador como (F) para Funarbe, e pessoa a entrevistada, como (E):

- (F) E o movimento da meia lua, pra que existe
isso? - (E) Pra fechar a caminho e pra abrir, se fazer a meia lua fechada, pra fechando o caminho pra outra guarda que vem atrás, se a gente faz ela aberta, a gente ta abrindo, deixando o caminho aberto pra guarda que vem.

- (F) Quando fecha a guarda, o que acontece com a guarda? 
- (E) Ela fica marrenta, ai se for esperto, vai fazer uma meia lua também pra abrir, ai quando a gente fecha, deixa a guarda mais presa no andar.

- (F) Quando uma guarda fecha, automaticamente vocês já percebem? Já fazem a meia lua aberta?

- (E) Já percebi

- (F) Então tem essas disputas dentro, e vocês fazem isso pra disputar ou pra testar, o que acontece? Como é isso?

- (E) Eu acho que acaba alguém testando, pra ver se o outro tá sabendo, o que num tá sabendo fica preso, ai tem que pedir ajuda pros orixás da frente e quando vê que a guarda ficou presa que tá atrás dele, eles mesmo fecham e eles mesmo abrem. Porque quando vê que a guarda que tá atrás não ta andando, é porque o da frente já fechou aquele, ai tem que voltar atrás, para, voltar e abrir o caminho [...] (Prefeitura Municipal de Betim et al., 2009, p.242).

Assim, mesmo havendo um preconceito religioso no interior da irmandade, parece não ser um consenso entre os congadeiros a ocorrência da supremacia da religião católica sobre a africana. Por isso, a medida adotada pela equipe da Funarbe em tentar minimizar esse conflito mostra-se positiva, para valorizar todas as práticas que fazem parte da manifestação. Por outro lado, certas disputas simbólicas estão incorporadas nas performances; então, a princípio, convém mesmo respeitá-las, e o Poder Público, por meio da Funarbe e do IEPHA, não deve interferir.

Enfim, será abordada a divulgação da manifestação, tema visto tanto pela Funarbe, quanto pelos congadeiros, como uma forma de valorizar o evento, contribuir para sua vitalidade. Os protagonistas do Reinado, em seus depoimentos, apontam que a divulgação é fraca, o que compromete até mesmo a participação de dançantes, nos ternos, conforme percebe-se em seus depoimentos transcritos:

Hoje em dia, nego chega perto de mim e pergunta: "quando que vai ser a festa de Nossa do Rosário? Acabou ontem. Ô meu Deus, eu tinha promessa para cumprir [...] "Mas porquê? Por causa da divulgação da festa é muito fraca é isso que nós tão recramando. Agora oce não vê a festa da feira da paz: passa na televisão, passa no rádio, passa no jornal, sai falando três, quatro mês antes! [...]. E agora guando chega nossa festa quando chega a esparramar o negocio tá em cima da hora, ninguém fica sabendo (Prefeitura Municipal de Betim et al., 2009, p.235).

Nas medidas de salvaguarda apresentadas no dossiê, há propostas de se fomentar uma divulgação da celebração, por meio de ações de educação patrimonial, publicações e participação das guardas em eventos públicos. Nesse sentido, nota-se uma compatibilidade de pensamento, apesar da crítica da pessoa entrevistada, e uma tentativa por parte da Funarbe em atender a sua reivindicação.

Enfim, sobre uma hierarquia discursiva encontrada na elaboração do dossiê de registro, o IEPHA ainda ocupa uma posição privilegiada, já que ele estabelece as diretrizes para as políticas de preservação do patrimônio em Betim, e daquele órgão depende a aprovação das medidas de salvaguarda, para que o Reinado seja fomentado e valorizado. Assim, os discursos registrados no dossiê são submetidos ao julgamento do IEPHA.

Entretanto, a Funarbe tem procurado atuar além das determinações do Instituto, já exercendo um trabalho com os congadeiros desde sua fundação, em 1987. Consequentemente, a instituição tem buscado outras parcerias, como o NEAD, para pensar outros mecanismos de proteção ao patrimônio cultural de Betim.

A atual gestão da Funarbe, que intermedia a relação entre os congadeiros e o IEPHA, respeita e valoriza as reivindicações dos protagonistas do Reinado, e procura destinar os recursos do ICMS Cultural para atender seus pedidos. O que, sob o ponto de vista da Fundação, gera preocupações, diferentemente do pensamento dos congadeiros. Desse modo, a Funarbe propõe solucionar os problemas detectados - dependência e enfraquecimento -, mas prestando referência aos valores dos congadeiros e buscando conciliar seus interesses, sem interferir de forma direta, mas também sem deixar de prestar assistência, seja financeira ou de prestação de serviços.

\section{Considerações Finais}

A ampliação do conceito de patrimônio cultural, contemplando sua dimensão intangível, possibilitou o contexto de produção para o registro do Reinado de Nossa Senhora do Rosário de Betim. 
As mudanças decorrentes na legislação própria para o patrimônio, assim como a execução de políticas públicas voltadas para este campo, propiciaram condições para a preservação de bens culturais até então negligenciados. Novos sujeitos sociais despontaram, quando suas práticas passaram a ser incluídas em categorias de patrimônio imaterial, e o pacto entre Estado e Sociedade deu espaço para outras entidades e indivíduos intermediarem esta relação, na seleção de bens a serem preservados. Outros critérios e outras técnicas precisaram ser construídos para abarcar as novas possibilidades de patrimônio, que contemplam uma diversidade de culturas, grupos e atividades.

Betim procurou se adequar a estas inovações, introduzindo-as nas ações exercidas pelo Poder Público Municipal, ao criar uma legislação jurídica apropriada, um conselho deliberativo para atuar em conjunto com órgãos públicos (tais como a Funarbe), criados exclusivamente para gerir o patrimônio cultural local. Houve a abertura de livros de registro de bens culturais de natureza intangível. Porém, a elaboração do dossiê de registro do Reinado da cidade se conduziu, preponderantemente, pela política de ICMS Cultural, aplicada pelo Governo do Estado de Minas Gerais, com destaque para a atuação do IEPHA.

Busca-se explicar a atuação dos sujeitos que participaram na elaboração do dossiê de Registro do Reinado de Nossa Senhora do Rosário de Betim, além do IEPHA e da Funarbe, tais como o Conselho Deliberativo do Patrimônio Cultural de Betim, o NEAD/UFMG, o CONEP, o Escritório Miguilim e os próprios congadeiros que atuam no Reinado. Contudo, a formação do dossiê se consolidou principalmente devido ao desempenho do IEPHA, pois este atribuiu um modelo do dossiê, um cronograma de trabalho; impôs uma produção documental e burocrática, e aprovou os mecanismos de repasse de verbas, mediante uma proposta de preservação e salvaguarda que a Funarbe deveria formular e, por conseguinte, o preenchimento dos campos do dossiê deveria estar adequado às exigências e normas daquele Instituto.

Entretanto, observa-se que a Funarbe, mesmo com a intervenção do IEPHA, já perpetrava um trabalho com a irmandade de Betim, na promoção da celebração do Reinado; buscou apoio e suporte em outras refe- rências e em outras entidades que possuíam uma experiência com a temática. Já atuava, também, em parceria com outros órgãos públicos da Prefeitura de Betim para fomento da celebração. Assim, a Fundação ultrapassou as fronteiras colocadas pelo IEPHA e procurou outros meios, inclusive financeiros, para o fomento da festa.

Outro ponto importante a ser assinalado: ao Reinado de Nossa Senhora do Rosário foi atribuído um título de patrimônio imaterial do município. Este título confere ao Poder Público Municipal um compromisso com a manifestação, em desenvolver continuamente mecanismos de salvaguarda e preservação do Reinado, que de uma manifestação religiosa passou a tornar-se um bem patrimonializado.

No dossiê da Funarbe, verifica-se que o discurso titular pertence ao Governo do Estado de Minas Gerais, representado pelo IEPHA, com a intermediação do CONEP e da Funarbe. O registro dos depoimentos dos "protagonistas" do Reinado, a princípio, foi feito para historicizar e descrever o bem cultural; mas a participação das lideranças do congado, apesar de fundamental para a celebração, se deu de forma secundária, respondendo às solicitações dos produtores do dossiê. Os outros atores, neste caso estudado, são representados pelos profissionais técnicos, que são da equipe daquela Fundação; mas também trabalharam os consultores terceirizados, como os arquitetos do Escritório Miguilim. Esses profissionais, tanto da Funarbe quanto do escritório, utilizaram seus conhecimentos técnicos, e recorreram a fontes bibliográficas e documentais, tais como trabalhos científicos, especialmente da História e das Ciências Sociais, para propiciar uma maior sustentação à parte escrita e teórica do dossiê. Dessa forma, indiretamente, há a participação de acadêmicos na construção do registro.

Nos depoimentos registrados, os congadeiros expuseram suas próprias expressões formuladas: pela linguagem, que representa as vivências e experiências cotidianas e biográficas; pela tradição religiosa, herdada por meio da transmissão oral.

Percebe-se uma maior incompatibilidade no registro da Funarbe, nos discursos dos congadeiros entre si e com relação à Fundação; principalmente no que concerne a dependência dos primeiros em relação ao segundo. Foi também explicitada a diferença entre as 
estruturas de registro, uma sendo deliberada pelo CONEP/IEPHA e a outra adotada pela Funarbe. As categorias dos livros de registro, consagradas em Betim, também têm suas especificidades, diferentes das adotadas pelo IPHAN e pelo IEPHA. Os conflitos internos entre as lideranças e as guardas igualmente foram mencionados, o que envolve divergências para assumir a direção da irmandade e resolver as contendas religiosas.

Na produção da Funarbe, os congadeiros foram coadjuvantes, pois depara-se com uma construção, em sua maior parte textual, de caráter descritivo e explicativo, produzido pela equipe daquela Fundação sob a orientação e aval do IEPHA.

O que não implica em afirmar que há uma delimitação rígida: no dossiê da Funarbe, encontra-se fotografias, filmagens antigas e depoimentos dos congadeiros, que também fundamentaram a construção do documento. E mesmo que haja uma considerável intervenção por parte do IEPHA e da Funarbe, os protagonistas do Reinado estão mais próximos da gestão deste último órgão e são mais ouvidos em suas reivindicações, exercendo uma participação mais ativa em parceria com os membros da fundação.

Ressalta-se que os recursos do ICMS Cultural têm sido continuamente destinados a salvaguarda da manifestação, mesmo questionando-se uma notada dependência que deve ser reconsiderada.

Os "protagonistas" do bem cultural, paradoxalmente, não se mostraram como os "protagonistas" do registro do dossiê, visto que sua participação mostrou ter sido mais reativa, e não de iniciativa; ou seja, apesar de serem os maiores interessados na preservação do Reinado, não foram eles que iniciaram o processo de elaboração do dossiê, nem participaram das decisões quando foram criados: os critérios que fundamentaram a seleção dos bens a serem preservados, os métodos de preservação e a formatação do dossiê.

\section{Referências}

Betim. Lei n².944, de 24 de setembro de 1996. Estabelece a proteção do patrimônio histórico e artístico de Betim, atendendo ao disposto no artigo 166, V da Constituição Estadual e Art. 161 da Lei Orgânica Municipal, e dá outras providências. In: Fundação Artístico Cultural de Betim. Dossiê de tombamento: Casa da Cultura Josephina Bento. Betim: Prefeitura Municipal, 1996.
Cada ator aqui apresentado teve um interesse a ser considerado: a Administração Pública, por consolidar o seu papel ainda primordial no processo decisório, inclusive na elaboração de políticas públicas de preservação do patrimônio cultural; os técnicos e acadêmicos, por exercerem e difundirem seus trabalhos e se firmarem como profissionais do serviço público e de mercado; e os próprios congadeiros, pois a celebração do Reinado tornou-se um bem cultural passível de preservação, atraindo a ação de políticas públicas para contribuir para a sua continuidade. Entretanto, há as contradições e os benefícios relativos a esta intervenção do Estado, na preservação do Reinado e do patrimônio imaterial como um todo, o que não foi proposto a ser tratado neste artigo.

Estas informações foram levantadas e analisadas como parte da tese em andamento "Os registros dos congados de Belo Horizonte e Betim: novas abordagens em relação à preservação do patrimônio cultural imaterial". Há conteúdos e discursos que precisam ser esmiuçados. Nesse sentido, mais ou outras conclusões podem ser formuladas, inclusive a respeito da intervenção do Estado na preservação do patrimônio imaterial.

O dossiê de registro é um documento em constante construção e, assim como qualquer prática sociocultural, sua elaboração está sempre por receber influências de diferentes contextos políticos e históricos; e adaptações, concessões, reelaborações, sempre propiciam um novo formato para o documento, o que deve ser feito mediante novos estudos e pesquisas. Outras metodologias de análise do registro podem ser propostas. No entanto, considera-se que a participação de diferentes olhares, ponderando-se o interesse de todos os envolvidos, sobretudo os praticantes dos bens registrados, é essencial. Principalmente para se observar, pela perspectiva deles, de como o registro - um arquivo estatal -, contribui efetivamente para a preservação do repertório que compõe o patrimônio cultural imaterial.

Betim. Decreto no 16.389, de 26 de outubro de 2000. Instituio registro de bens culturais de natureza imaterial, que constituem o patrimônio cultural de Betim. Betim: Funarbe, 2000.

Brasil. Alimento: direito sagrado - pesquisa socioeconômica e cultural dos povos e comunidades tradicionais de terreiros. 2011. Disponível em: <http://www.mds.gov.br/sesan/ terreiros/paginas/inicio.htm>. Acesso em: 16 maio 2012. 
Brasil. Decreto no 3.551, de 4 de agosto de 2000. Institui o registro de bens culturais de natureza imaterial que constituem patrimônio cultural brasileiro, cria o Programa Nacional do Patrimônio Imaterial e dá outras providências. Disponível em: <http://www.revistamuseu.com.br/legislacao/cultura/ decreto3551.htm>. Acesso em: 16 set. 2007.

Castriota, L.B.; Rugani, J.M. Inventário do patrimônio urbano e cultural de Betim. Academia.edu, 1999. Disponível em: <http:// www.academia.edu/1177479/Inventario_do_Patrimonio_ Urbano_e_Cultural_de_Betim>. Acesso em: 13 fev. 2012.

Conselho Estadual do Patrimônio Cultural. Informações sobre o CONEP. [200-?]. Disponível em: <http://www.conselhos. mg.gov.br/conep/>. Acesso em: 3 jun. 2012.

Fonseca, M.C.L. O patrimônio em processo: trajetória da política federal de preservação no Brasil. Rio de Janeiro: IPHAN, 1997.

Foucault, M. Arqueologia do saber. Petrópolis: Vozes, 1972.

Gomes, A.C.G. O registro das dimensões intangíveis como fator de preservação do patrimônio cultural de Betim. In: Se- minário Regional sobre Patrimônio Cultural da Região Metropolitana de Belo Horizonte: Cidades, Memória, Sustentabilidade, Desenvolvimento Local, 2, 2011, Betim. Anais... Betim: Prefeitura Municipal de Betim, 2011. p.115-120.

Instituto Estadual de Patrimônio Histórico de Minas Gerais. Deliberação normativa no 1, de 30 de junho de 2009. Belo Horizonte: IEPHA, 2009. Disponível em: <www.iepha. gov.br>. Acesso em: 3 jun.2012.

Minas Gerais (Estado). Lei no 18.030, de 12 de janeiro de 2009. Dispõe sobre a distribuição da parcela da receita do produto da arrecadação do ICMS pertencente aos municípios. Diário Oficial do Estado, 13 jan. 2009. Disponível em: <http://www. fazenda.mg.gov.br/empresas/legislacao_tributaria/leis/2009/ |18030_2009.htm>. Acesso em: 26 set. 2009.

Prefeitura Municipal de Betim, et al. Reinado de Nossa Senhora do Rosário: dossiê de registro de bem cultural material. Betim: Funarbe, 2009

Prefeitura Municipal de Betim. Cadernos da memória: Reinado de Nossa Senhora do Rosário. Betim: Funarbe, 2010. 